\title{
Energy Disorder in Liquid Fe-Si Alloy
}

\author{
D. Adhikari' ${ }^{1}$ I.S. Jha ${ }^{1}$ and B.P. Singh ${ }^{2}$ \\ ${ }^{1}$ Dept. of Physics, M.M.A.M. Campus (Tribhuvan University), Biratnagar, Nepal \\ ${ }^{2}$ Univ. Dept. of Physics, T.M.Bhag. University, Bhagalpur, Bihar, India \\ Corresponding author: adksbdev@yahoo.com
}

\begin{abstract}
The observed asymmetry in the properties of mixing of Fe-Si alloy in molten state is successfully explained on the basis of regular associated solution model. We have determined the free energy of mixing, heat of mixing and entropy of mixing of Fe-Si alloys in molten state at $1873 \mathrm{~K}$. The analysis suggests that heterocoordination leading to the formation of complex $\mathbf{E}{ }_{2} \mathrm{~S}$ is likely to exist in the liquid and is of a strongly interacting nature. The theoretical analysis reveals that the pairwise interaction energies between the species depend considerably on temperature.
\end{abstract}

Keywords: Liquid alloy; clusters; thermodynamic properties

\section{Introduction}

The asymmetric behaviour of mixing properties of the binary alloys may be attributed to the strong interactions present in it $[2,3]$.Large negative excess free energy of mixing, entropy of mixing and heat of mixing with a sharp change in slope near compound forming concentrations are the characteristics of the compound forming alloys $[4,5]$. The formation of compound in solid state led many theoreticians [6-8] to believe that chemical complexes might exist in molten state. These complexes are given different names, such as 'pseudomolecules', 'clusters', 'complexes' etc. Various models based on the above assumptions [8-10] are being used to understand the alloying behaviouur of binary alloys. We intend to use regular associated model to explain the alloying behaviour of Fe-Si alloys in molten state at 1873K. The phase diagram suggests that $\mathrm{Fe}_{2} \mathrm{Si}$ complexes exist in solid state [1].

In the next section, the basic expression for the formalism used in the calculation is presented. Section 3 gives the results and discussion of this work and the conclusions are outlined in section 4 .

\section{Formalism}

Let there be three species in equilibrium in the liquid alloy, namely, monomers $\mathrm{A}(=\mathrm{Fe}), \mathrm{B}(=\mathrm{Si})$ and $\mathrm{A}_{\mathrm{p}} \mathrm{B}$ $\left(=\mathrm{Fe}_{2} \mathrm{Si}\right)$ molecules in the respective concentrations $\mathrm{n}_{\mathrm{A}}, \mathrm{n}_{\mathrm{B}}$, and $\mathrm{n}_{\mathrm{ApB}}$ moles. Considering a solution of $\mathrm{n}_{1}$ atoms of $A$ and $n_{2}$ atoms of $B$, the formation of $n_{A p B}$ complex requires $\mathrm{n}_{1}=\mathrm{n}_{\mathrm{A}}+\mathrm{p}_{\mathrm{ApB}}$ and $\mathrm{n}_{2}=\mathrm{n}_{\mathrm{B}}+\mathrm{n}_{\mathrm{ApB}}$ for conservation of mass in the partially associated solution. When there is association, the thermodynamic behaviour of complexes A and B components is governed by their true mole fractions $\mathrm{x}_{\mathrm{A}}, \mathrm{x}_{\mathrm{B}}$ and $\mathrm{x}_{\mathrm{ApB}}$ rather than their gross mole fraction $\mathrm{x}_{1}$ and $\mathrm{x}_{2}$, where

$$
\begin{gathered}
\mathrm{x}_{1}=\frac{\mathrm{n}_{1}}{\mathrm{n}_{1}+\mathrm{n}_{2}}, \mathrm{x}_{2}=\frac{\mathrm{n}_{2}}{\mathrm{n}_{1}+\mathrm{n}_{2}} \\
\mathrm{x}_{\mathrm{A}}=\frac{\mathrm{n}_{\mathrm{A}}}{\mathrm{n}_{\mathrm{A}}+\mathrm{n}_{\mathrm{B}}+\mathrm{n}_{\mathrm{ApB}}}, \mathrm{x}_{\mathrm{B}}=\frac{\mathrm{n}_{\mathrm{B}}}{\mathrm{n}_{\mathrm{A}}+\mathrm{n}_{\mathrm{B}}+\mathrm{n}_{\mathrm{ApB}}} \text { and } \mathrm{x}_{\mathrm{ApB}}=\frac{\mathrm{n}_{\mathrm{ApB}}}{\mathrm{n}_{\mathrm{A}}+\mathrm{n}_{\mathrm{B}}+\mathrm{n}_{\mathrm{ApB}}}
\end{gathered}
$$

Using equations (1) and (2) the two sets of mole fractions are related to each other by the relations

$$
\mathrm{x}_{\mathrm{A}}=\mathrm{x}_{1}-\mathrm{px}_{2} \mathrm{x}_{\mathrm{ApB}}, \mathrm{x}_{\mathrm{B}}=\mathrm{x}_{2}-\left(1-\mathrm{px}_{2}\right) \mathrm{x}_{\mathrm{ApB}}
$$

Progonine and Defay [11] have shown that in associated solutions, the gross chemical potentials of components 1 and 2 are equal to the chemical potentials of the monomeric species A and B. Following Jordan [7] the activity coefficients $\tilde{a}_{A}, \tilde{a}_{B}$ and $\tilde{a}_{A p B}$ of monomers and complex can be expressed in terms of pairwise interaction energies through

$$
\begin{aligned}
& \text { RT 1n } \gamma_{\mathrm{A}}=\mathrm{x}_{\mathrm{B}}^{2} \omega_{12}+\mathrm{x}_{\mathrm{ApB}}^{2} \omega_{13}+\mathrm{x}_{\mathrm{B}} \mathrm{x}_{\mathrm{ApB}}\left(\omega_{12}-\omega_{23}+\omega_{13}\right) \\
& \text { RT 1n } \gamma_{\mathrm{B}}=\mathrm{x}_{\mathrm{ApB}}^{2} \omega_{23}+\mathrm{x}_{\mathrm{A}}^{2} \omega_{12}+\mathrm{x}_{\mathrm{A}} \mathrm{x}_{\mathrm{ApB}}\left(\omega_{23}-\omega_{13}+\omega_{12}\right) \\
& \text { RT 1n } \gamma_{\mathrm{ApB}}=\mathrm{X}_{\mathrm{A}}^{2} \omega_{13}+\mathrm{x}_{\mathrm{b}}^{2} \omega_{23}+\mathrm{x}_{\mathrm{B}} \mathrm{X}_{\mathrm{ApB}}\left(\omega_{13}-\omega_{12}+\omega_{23}\right)(4 \mathrm{c})
\end{aligned}
$$
where $\grave{\mathrm{u}}_{\mathbb{R}}$, $\grave{\mathrm{u}}_{B}$ and $\mathrm{u}_{B}$ are interaction energies for the species $\mathrm{A}, \mathrm{B} ; \mathrm{A}, \mathrm{A}_{\mathrm{p}} \mathrm{B}$ and $\mathrm{B}, \mathrm{A}_{\mathrm{p}} \mathrm{B}$ respectively, $\mathrm{T}$ the temperature and $\mathrm{R}$ stands for the universal gas constant.

The equilibrium constant for the reaction $\mathrm{A}_{\mathrm{p}} \mathrm{B} \Leftrightarrow \mathrm{pA}+\mathrm{B}$ is given by

$$
\mathrm{k}=\frac{\mathrm{x}_{\mathrm{A}}^{\mathrm{p}} \mathrm{x}_{\mathrm{B}} \tilde{\mathrm{a}}_{\mathrm{A}}^{\mathrm{p}} \tilde{\mathrm{a}}_{\mathrm{B}}}{\mathrm{x}_{\mathrm{ApB}} \mathrm{x}_{\mathrm{ApB}}}
$$

Thus, using equation (3), (4) and (5), one gets

$\ln \mathrm{k}=\mathrm{h}\left(\frac{\mathrm{x}_{\mathrm{A}}^{\mathrm{P}} \mathrm{x}_{\mathrm{B}}}{\mathrm{x}_{\mathrm{ApB}}}\right)+\frac{\omega_{12}}{R T}\left[\mathrm{px}_{\mathrm{B}}\left(1-\mathrm{x}_{\mathrm{B}}\right)+\mathrm{x}_{\mathrm{A}}\right]+\frac{\omega_{13}}{R T}\left[\mathrm{px}_{\mathrm{ApB}}\left(1-\mathrm{x}_{\mathrm{A}}\right)-\mathrm{x}_{\mathrm{A}}\right]+\frac{\omega_{23}}{R T}\left[\mathrm{x}_{\mathrm{ApB}}\left(1-\mathrm{px}_{\mathrm{B}}\right)-\mathrm{x}_{\mathrm{B}}\right]$

Now using the equations listed above the integral excess free energy $\Delta \mathrm{G}^{\mathrm{xs}}$ is given by 


$$
\begin{aligned}
\Delta \mathrm{G}^{\mathrm{XS}}= & \frac{1}{\left(1+\mathrm{px}_{\mathrm{APB}}\right)}\left(\mathrm{x}_{\mathrm{A}} \mathrm{x}_{\mathrm{B}} \omega_{12}+\mathrm{x}_{\mathrm{A}} \mathrm{x}_{\mathrm{APB}} \mathrm{\omega}_{13}+\mathrm{x}_{\mathrm{B}} \mathrm{x}_{\mathrm{APB}} \omega_{23}\right)+\frac{\overline{R T}}{\left(1+\mathrm{px}_{\mathrm{APB}}\right)} \times \\
& \left(\mathrm{x}_{\mathrm{A}} \mathrm{hx}_{\mathrm{A}}+\mathrm{x}_{\mathrm{B}} \mathrm{hx}_{\mathrm{B}}+\mathrm{x}_{\mathrm{APB}} \mathrm{hx}_{\mathrm{ApB}}\right)-R T\left(\mathrm{x}_{1} \ln \mathrm{x}_{1}+\mathrm{x}_{2} \ln \mathrm{x}_{2}\right)+\frac{\mathrm{x}_{\mathrm{ApB}}}{\left(1+\mathrm{px}_{\mathrm{ApB}}\right)} \mathrm{RT} \ln \mathrm{k}
\end{aligned}
$$

Once the expressions for $\Delta \mathrm{G}\left[=\Delta \mathrm{G}^{\mathrm{XS}}+\mathrm{RT}\left(\mathrm{x}_{1} \ln \mathrm{x}_{1}+\mathrm{x}_{2} \ln \mathrm{x}_{2}\right)\right]$ is obtained, other thermodynamic and microscopic functions follow readily. Heat of mixing and entropy of mixing are related to $\Delta \mathrm{G}$ through standard thermodynamic relations

$$
\begin{gathered}
\Delta \mathrm{H}=\Delta \mathrm{G}-\mathrm{T}\left(\frac{\partial \Delta \mathrm{G}}{\partial \mathrm{T}}\right)_{\mathrm{T}, \mathrm{P}} \\
\Delta \mathrm{S}=\frac{\Delta \mathrm{H}-\Delta \mathrm{G}}{\mathrm{T}}
\end{gathered}
$$

where $\mathrm{C}\left(=\mathrm{x}_{\mathrm{Fe}}\right)$ is concentration of $\mathrm{A}$ component in the alloy. Using equation (7) in equation (8), we obtained expressions for $\Delta \mathrm{H}$ as

$$
\begin{aligned}
& \Delta \mathrm{H}=\frac{1}{\left(1+\mathrm{pX}_{\mathrm{ApB}}\right)}\left(\mathrm { x } _ { \mathrm { A } } \mathrm { X } _ { \mathrm { B } } \left(\mathrm{O}_{2}+\mathrm{x}_{\mathrm{A}} \mathrm{X}_{\mathrm{ApB}}\left(\mathrm{O}_{13}+\mathrm{X}_{\mathrm{B}} \mathrm{X}_{\mathrm{ApB}}\left(\mathrm{O}_{23}\right)-\frac{\mathrm{T}}{\left(1+\mathrm{px}_{\mathrm{ApB}}\right)} \times\right.\right.\right. \\
& \left(x_{A} x_{B} \frac{\partial \omega_{12}}{\partial T}+x_{A} x_{A p B} \frac{\partial \omega_{13}}{\partial T}+x_{B} X_{A p B} \frac{\partial \omega_{23}}{\partial T}\right)-\frac{x_{A p B}}{\left(1+p x_{A P B}\right)} R T^{2} \frac{d \ln k}{d T}
\end{aligned}
$$

The pairwise interaction energies and equilibrium constant are determined by the following method:

In a regular associated solution $\mathrm{x}_{1} \gamma_{1}=\mathrm{x}_{\mathrm{A}} \gamma_{\mathrm{A}}$ and $\mathrm{x}_{2} \gamma_{2}=\mathrm{x}_{\mathrm{B}} \gamma_{\mathrm{B}}$, where $\gamma_{1}$ and $\gamma_{2}$ are respective gross activity coefficients of components 1 and 2. Thus

and

$$
\ln \gamma_{1}=\ln \gamma_{\mathrm{A}}+\ln \frac{\gamma_{\mathrm{A}}}{\mathrm{x}_{1}}
$$

$$
\ln \gamma_{2}=\ln \gamma_{\mathrm{B}}+\ln \frac{\gamma_{\mathrm{B}}}{\mathrm{x}_{2}}
$$

The pairwise interaction energies, the equilibrium constants and the activity coefficients at infinite dilution can be written as [8]

$$
\begin{aligned}
& \ln \gamma^{\circ}=\frac{\omega_{12}}{\mathrm{RT}} \\
& \mathrm{k} \exp \left(\omega_{13} / \mathrm{RT}\right)=\frac{\gamma_{1}^{\mathrm{o}} \gamma_{2}^{\mathrm{o}}}{\gamma_{1}^{\mathrm{o}}-\gamma_{2}^{\mathrm{o}}}
\end{aligned}
$$

Where $\gamma_{1}^{\circ}$ and $\gamma_{2}^{\circ}$ are activity coefficients of component $\mathrm{A}$ and that of $\mathrm{B}$ at zero concentrations.

Solving equations (4a) and (4b) we obtain

$$
\begin{aligned}
& \frac{\omega_{3}}{\mathrm{RT}}=\frac{\mathrm{x}_{\mathrm{B}} \mathrm{h}\left(\frac{\mathrm{a}_{2}}{\mathrm{x}_{\mathrm{B}}}\right)+\left(1-\mathrm{x}_{\mathrm{B}}\right) \mathrm{h}\left(\frac{\mathrm{a}_{1}}{\mathrm{x}_{\mathrm{A}}}\right)-\mathrm{x}_{\mathrm{B}}\left(1-\mathrm{x}_{\mathrm{B}}\right) \frac{\omega_{\mathrm{P}}}{\mathrm{RT}}}{\mathrm{x}_{\mathrm{ApB}}^{2}} \\
& \frac{\omega_{13}}{\mathrm{RT}}=\frac{\mathrm{x}_{\mathrm{A}} \ln \left(\frac{\mathrm{a}_{1}}{\mathrm{x}_{\mathrm{A}}}\right)+\left(1-\mathrm{x}_{\mathrm{A}}\right) \ln \left(\frac{\mathrm{a}_{2}}{\mathrm{x}_{\mathrm{B}}}\right)-\mathrm{x}_{\mathrm{A}}\left(1-\mathrm{x}_{\mathrm{A}}\right) \frac{\omega_{12}}{\mathrm{RT}}}{\mathrm{x}_{\mathrm{ApB}}^{2}}
\end{aligned}
$$

Using equations (6), (13) and (14), we can derive

$\ln \mathrm{k}+\frac{\omega_{13}}{\mathrm{RT}}=\left(\frac{1+\mathrm{x}_{\mathrm{A}}}{\mathrm{x}_{\mathrm{ApB}}}\right) \ln \left(\frac{\mathrm{a}_{1}}{\mathrm{x}_{\mathrm{A}}}\right)+\frac{\mathrm{x}_{\mathrm{B}}}{\mathrm{x}_{\mathrm{ApB}}}\left[\ln \left(\frac{\mathrm{a}_{2}}{\mathrm{x}_{\mathrm{B}}}\right)-\frac{\omega_{12}}{\mathrm{RT}}\right]+\ln \left(\frac{\mathrm{a}_{1}^{\mathrm{p}} \mathrm{a}_{2}}{\mathrm{x}_{\mathrm{ApB}}}\right)(15)$

\section{Results and Discussion}

The mole fraction $\mathrm{x}_{\mathrm{E}_{2} \mathrm{~S}}$ of complex $\mathrm{E}_{2} \mathrm{~S}$ is determined using experimental data of activity [1] and equations (12) and (15) employing the iterative procedure. The compositional dependence of various species (figure 1) shows that the maximum association occurs at 69 at. pct. of Fe. At this composition and $1873 \mathrm{~K}$, about 39 mol pct. of the liquid alloy is associated.

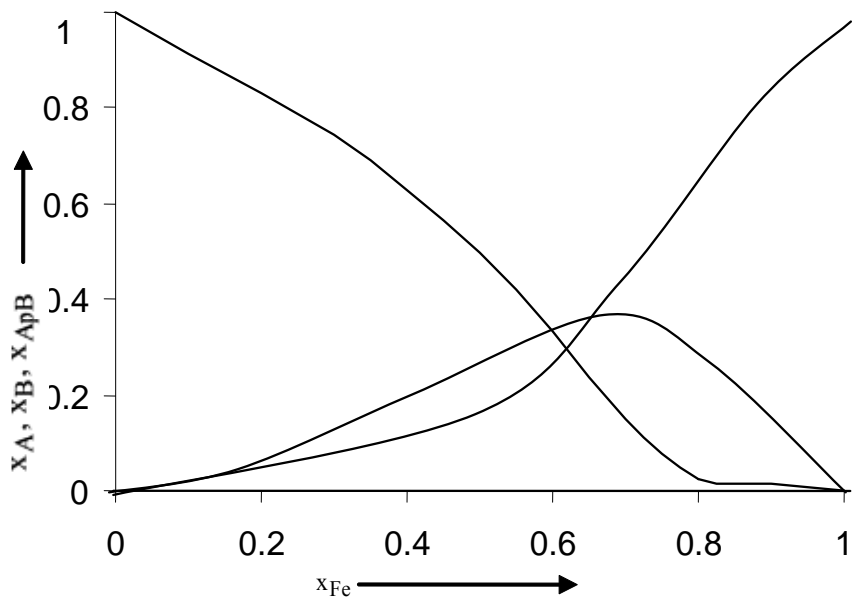

Figure-1

Compositionaldependenceofmolefractions $\mathrm{x}_{\mathrm{A}}(\mathrm{A}=\mathrm{Fe}), \mathrm{x}_{\mathrm{B}}(\mathrm{B}=\mathrm{Si})$ and $\mathrm{x}_{\mathrm{ApB}}\left(\mathrm{A}_{\mathrm{P}} \mathrm{B}=\mathrm{Fe}_{2} \mathrm{Si}\right.$ ) versus $\mathrm{x}_{\mathrm{Fe}}$ (concentration of $\mathrm{Fe}$ ) at $1873 \mathrm{~K}$

The equilibrium constant and pairwise interaction energies are estimated from the equations (6), (11a), (14), (15) and observed data for integral excess free energy of mixing [1]. The equilibrium constant and interaction energies for the alloy $\mathrm{Fe}_{2} \mathrm{Si}$ in liquid state at $1873 \mathrm{~K}$ are found to be

$$
\begin{gathered}
\mathrm{k}=4.139 \times 10^{-3}, \omega_{12}=-64170 \mathrm{~J} \mathrm{~mol}^{-1}, \omega_{13}=-14720 \mathrm{~J} \\
\mathrm{~mol}^{-1} \text { and } \omega_{23}=-45500 \mathrm{~J} \mathrm{~mol}^{-1}
\end{gathered}
$$

All the interaction energies are large negative value and show that $\mathrm{Fe}$ and $\mathrm{Si}$ atoms are strongly attracted to each other and to the complex.

Theoretical calculation of free energy of mixing for Fe$\mathrm{Si}$ liquid alloy shows that $\mathrm{Fe}-\mathrm{Si}$ alloy in liquid state is strongly interacting system. Figure 2 shows very good a good agreement between calculated and experimental free energy of mixing. 


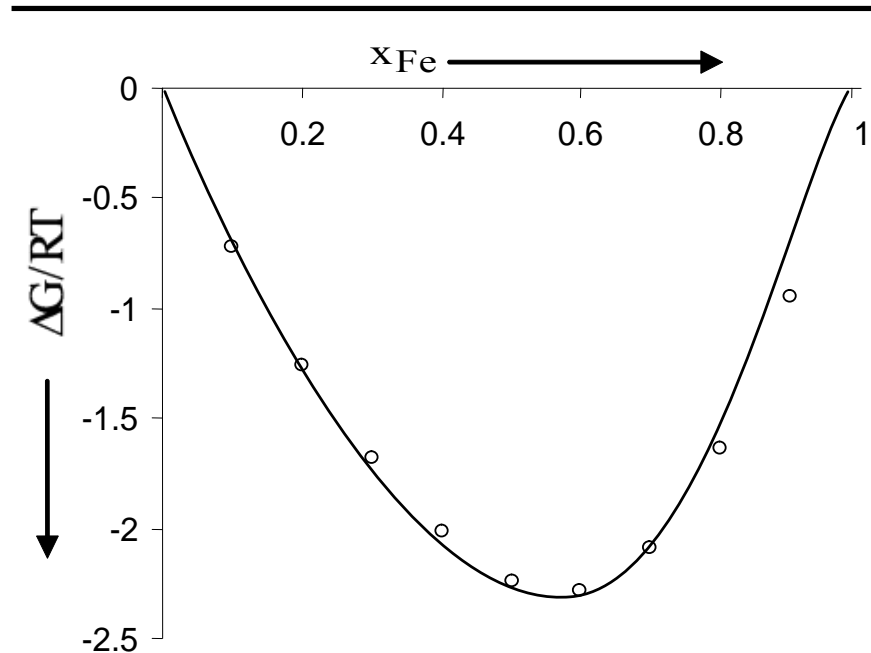

Figure-2

Free energy of mixing $(\Delta \mathrm{G} / \mathrm{RT})$ versus $\mathrm{x}_{\mathrm{Fe}}$ of liquid $\mathrm{Fe}-\mathrm{Si}$ solution $(1873 \mathrm{~K})$; (-) theory, (००) experiment [1]

We have observed that if the interaction energies are supposed to be independent of temperature, i.e.,

$\frac{\partial \omega_{12}}{\partial T}=0$ etc., then $\Delta \mathrm{H}$ and $\Delta \mathrm{S}$ so obtained are in poor agreement with experimental data. This simply suggests importance of the dependence of interaction energies on temperature. On using equation (10) and observed values of $\Delta \mathrm{H}$ [1] we have chosen the following values for the given parameters as the best fit values for the heat of formation of $\mathrm{Fe}_{2} \mathrm{Si}$ complex.

$$
\begin{gathered}
\frac{\partial \omega_{12}}{\partial \mathrm{T}}=-45 \frac{\partial \omega_{13}}{\partial \mathrm{T}}=\frac{\partial \omega_{23}}{\partial \mathrm{T}}=0 \text { and } \mathrm{RT}^{2} \frac{\partial \ln \mathrm{k}}{\partial \mathrm{T}}= \\
185000 \pm 2500 \mathrm{~J} \mathrm{~mol}^{-1}
\end{gathered}
$$

It is found from the analysis that the heat of mixing is negative at all concentration. Our theoretical calculation shows that the minimum value of the heat of mixing is -2.585 at $\mathrm{x}_{\mathrm{Fe}}=0.55$. Further it is observed that the concentration dependence of asymmetry in $\Delta \mathrm{H}$ can be explained only when one considers the temperature dependent of the pairwise interaction energies. Figure 3 and 4 show the comparison between the experimental and calculated values of heat of mixing and entropy of mixing.



Figure -3

Heat of mixing $\left(\Delta \mathrm{H} / \mathbb{R}\right.$ ) versus $\mathrm{X}_{\mathrm{Fe}}$ of liquid Fe-Si solution $(1873 \mathrm{~K}) ;(-)$ theory, $(\circ \circ)$ experiment [1]

$$
0.3
$$

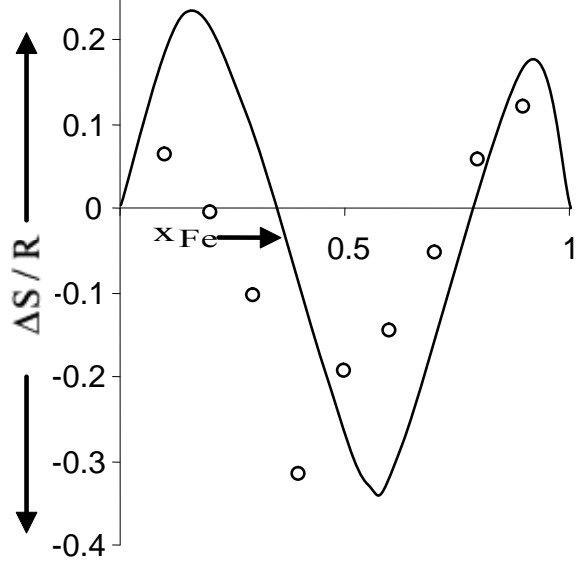

Figure-4

Entropy of mixing $(\triangle \mathrm{S} / \mathrm{R})$ versus $\mathrm{x}_{\mathrm{Fe}},(1873 \mathrm{~K})$; $(-)$ theory, (०००) experiment [1]

\section{Conclusion}

In present work, we have used regular associated solution model to obtain equilibrium constant, pairwise interaction energies for $\mathrm{E}_{2} \mathrm{~S}$ liquid alloy at $1873 \mathrm{~K}$. The knowledge of nature and extent of interaction energies between the components and complex have been used for the estimation of thermodynamic properties of $\mathrm{E}_{2} \mathrm{~S}$ alloy in liquid state. The analysis also shows that the $\mathrm{Fe}-\mathrm{Si}$ system is strongly interacting heterocoordination system. The pairwise interaction energies of this system depend on temperature. 


\section{Acknowledgement}

One of the authors (D. Adhikari) is thankful to University

Grant Commission (UGC), Nepal, for providing financial support to pursue the research.

\section{References}

[1]. R. Hultgren, P. D. Desai, D.T. Hawkins, M. Gleiser and K.K. Kelly, Selected Values of the

Thermodynamic Properties of Binary Alloys (ASM,Metal Park)1973.

[2]. W.H. Young, Rep. Prog. Phys. 55(1992) 1769

[3]. R. N. Singh and N. H. March, in: Intermetallic Compounds, Vol.1-Principle, eds, J.H.

Westbrook and R.L. Fleischer (Wiley, New York, 1994) 661 .
[4]. N.H. March, Liqiid Metals, concept and Theory (Cambridge University Press, Cambridge, (1990)

[5]. R.N. Singh, Can J. Phys. 65 (1987) 309.

[6]. A. B. Bhatia and R.N. Singh, Phys. Chem. Liq. 11(1982) 285.

[7]. A.S. Jordan, Metall. Trans. 1 (1970) 239

[8]. S. Lele and P. Ramchandra Rao, Metall. Trans. 12 B (1981) 659

[9] I.S. Jha, R. N. Singh, P.L. Shrivastava and N.R. Mitra, Phil. Mag. 61(1990).

[10] C.N. J. Wargner, J. Rapidly Quenched Met. BV (1985) 405.

[11] I. Prigogine and R. Defay, Chemical thermodynamics, Longmans $\mathrm{G}$ reen and Co. London (1954) 257. 